\title{
Hemorrhagic Stroke: Clinical, Etiologic and Evolutive Aspects in Senegalese Children
}

Marième Soda Diop-Sène, Cissé Ousmane*, Moustapha Ndiaye, El-Hadj Malick Diouf, El-Hadj Makhtar Ba, Ngor Side Diagne, Amadou Gallo Diop and Mouhamadou Mansour Ndiaye

Neurology Department, Fann Teaching Hospital, Fann Avenue, Sheikh Cheikh Anta Diop BP: 5035, Dakar, Senegal

"Corresponding author: Cisse Ousmane, Neurology Department Fann Teaching Hospital, Fann Avenue, Sheikh Cheikh Anta Diop BP: 5035, Dakar, Senegal, Tel: 0022177 507.87.51; E-mail: ouscis01@hotmail.fr

Rec date: Aug 26, 2016; Acc date: Sep 20, 2016; Pub date: Sep 25, 2016

Copyright: (c) 2016 Diop-Sène MS, et al. This is an open-access article distributed under the terms of the Creative Commons Attribution License, which permits unrestricted use, distribution, and reproduction in any medium, provided the original author and source are credited.

\begin{abstract}
Introduction: Hemorrhagic Stroke (HS) are uncommon among children. They have an etiological specificity and different risk factors that are different from those of adults. Prognosis depends on the etiology. Our objective was to study the characteristics of children's HS in Senegal.

Methodology: Descriptive retrospective study from July 2003 to February 2014.

Results: 13 patients were collected, including 9 boys. The mean age was 9.85 years. The antecedents were: rheumatic heart disease ( 2 patients); congenital heart disease (1 patient); arterial hypertension systolic-diastolic untreated ( 1 patient); heterozygous sickle cell anemia ( 1 patient). No history for ( 8 patients $-61.53 \%$ ). The beginning was sudden or rapidly progressive in all patients. Clinical manifestations were hemiplegia $(53.84 \%)$, headache and vomiting $(46.15 \%)$, consciousness disorders $(30.76 \%)$, partial motor seizures $(7.69 \%)$. The topography was supratentorial $(84.61 \%)$. The causes were: arteriovenous malformations (3 patients); severe thrombocytopenia ( 1 patient); systolic-diastolic arterial hypertension (1 patient); myeloblastic leukemia (1 patient). No etiology (7 patients). 4 patients died during the acute phase. 1 patient was transferred to pediatric oncology. 1 patient was transferred abroad for embolization. The mean follow-up was 11.8 months. Outcome was favorable in patients with ad integrum restitution. 7 patients had hemiparesis type of neurological sequelae (4 patients), motor partial epilepsy (4 patients) and aphasia (1 patient). 1 patient developed hydrocephalus. No recurrence was noted.
\end{abstract}

Conclusion: This study provides a better diagnostic and etiological approach for better management.

Keywords: Hemorrhagic stroke; Children; Senegal

\section{Introduction}

Hemorrhagic strokes (HS) characterize any secondary clinical abnormalities in spontaneous rupture of a blood vessel in the brain parenchyma. The child's HS are relatively rare and have etiological specificity and risks factors that differ from those of adults. The objectives of this study are to investigate the clinical, paraclinical and evolutionary aspects of hemorrhagic strokes of child in Senegal [1-4].

\section{Patients and Methods}

\section{Study type}

We performed a retrospective descriptive study of all children hospitalized for hemorrhagic stroke from July 2003 to February 2014. HS cases were collected in Neurology and Neurosurgery departments of Fann Teaching hospital, Albert Royer children Hospital and Le Dantec children hospital in Dakar, Senegal. All patients aged 1 month to 18 years hospitalized for hemorrhagic stroke (clinical and radiological diagnosis) were included in the study. New-borns and patients whose files were incomplete were excluded.

\section{Methodology}

We collected all the biographical data (age, gender), clinical (age of onset, start mode, functional and physical signs) and patient's progression. All patients received a CT scan and/or brain MRI. According to the etiology, other paraclinical investigations were made. Statistical analysis was done using excel software (version 2010).

\section{Results}

We collected 13 children, 09 boys and 04 girls with a sex-ratio of 2.25 in favor of boys. 10 patients (76.91\%) were aged between 7 and 18 years and the rest (23.07\%) were between 2 months and 3 years.

The history found in patients were rheumatic heart disease (2 patients), congenital heart disease of type double interventricular cavitary communication and sub aortic (1 patient), a systolic-diastolic arterial hypertension untreated (1 patient) and heterozygous sickle cell disease (AS) (1 patient). 8 patients $(61.53 \%)$ showed no pathological antecedent upon occurrence of stroke.

The average age of onset of hemorrhagic stroke was 9.85 years with extremes of 2 months and 18 years [5-9]. The onset of symptoms was sudden or rapidly progressive in a few hours in all patients. Clinical signs were dominated by hemiplegia $(53.84 \%)$, headache and vomiting $(46.15 \%)$ and impaired consciousness $(30.76 \%)$. The partial motor seizures (7.69\%) were rare (Tables 1-3). All patients received a brain 
imaging (CT and/or MRI) and brain hemorrhages preferentially sat on the supratentorial floor (84.61\%), most rarely on the sub-tentorial floor (15.38\%). The identified causes were arteriovenous malformations (3 patients), severe thrombocytopenia (1 patient), a systolic-diastolic arterial hypertension (1 patient), and myeloid leukemia (1 patient). For 3 cases of arteriovenous malformations objectified by imaging (Magnetic Resonance Imaging), the nidus was in the middle cerebral artery (MCA) territory in 2 patients and in the posterior fossa in 1 patient. In 7 patients, no specific etiology has been identified due to lack of appropriate vascular explorations. The management was essentially symptomatic in neurological and/or neurosurgery department. The evolution was marked by deaths in acute phase of a massive cerebral hemorrhage. Two transfers in pediatric oncology and abroad for embolization of an arteriovenous malformation occurred. At discharge from hospital, seven patients had neurological deficits and among them 2 patients were subsequently lost from sight and 5 other regularly monitored with an average duration of follow-up of 11.8 months with extremes of 4 and 24 months. Among them, one (1) patient had a favorable evolution with ad integratum restitution, 4 patients had sequelae such as hemiparesis (3 patients), motor partial epilepsy (4 patients) and Broca's aphasia (1 patient). Of these 4 patients, one (1) had developed hydrocephalus, secondarily requiring ventriculo-peritoneal shunt. No cases of recurrence were noted in our series.

\begin{tabular}{|l|l|l|}
\hline Age & Number & Percentage (\%) \\
\hline 2 months & 3 & 23.07 \\
\hline 7 to 12 yrs & 4 & 30.76 \\
\hline 3 to 18 yrs & 6 & 46.15 \\
\hline
\end{tabular}

Table 1: Apportionment according to the visible signs.

\begin{tabular}{|c|c|c|}
\hline Neurological signs & Absolute values & Percentage (\%) \\
\hline Hemiplegia & 7 & \\
\hline Driving partial crisis & 1 & 7.69 \\
\hline Broca aphasia & 1 & 7.69 \\
\hline Coma & 4 & 30.76 \\
\hline Frontal Syndrome & & \\
\hline Headaches & 6 & 46.15 \\
\hline Vomiting & 6 & 46.15 \\
\hline Neck rigidity & 1 & 7.69 \\
\hline Cerebellar ataxia & 1 & 7.69 \\
\hline Supratentorial localization & $-84.61 \%$ & 84.61 \\
\hline Sub tentorial localization & $-15.39 \%$ & 15.39 \\
\hline
\end{tabular}

Table 2: Apportionment according to the manifestations of stroke.

\section{Discussion}

Hemorrhagic strokes are rare in children [1-4] with an annual incidence estimated between 1.1 to $2.3 / 100,000$. Our series of 13 cases in 11 years confirms the epidemiological reality. The cerebral hemorrhage can occur at all pediatric ages but with a peak between 5.6 years and 8.7 years (5.25) [5-9]. The average age of onset in our study was slightly higher with 9.85 years. The other epidemiological reality was male predominance between 51 and $66 \%[4,10]$.

Clinical signs were dominated by headache and vomiting, that are evidences of intracranial pressure (ICP) and hemiplegia, both in our series as in literature. Headache and vomiting are reported in $58-76 \%$ of patients and hemiplegia in 16.2 to $62 \%$ of patients [4,5,10,11-13]. These clinical signs often reflect the location of the hemorrhage which is supratentorial at 73.4 to $92.85 \%$ of reported cases $[4,8,14]$ and in $84.61 \%$ of children in our series. These are cerebral vascular malformations, first and foremost the arteriovenous malformations, which are the main causes of HS in children, in a proportion of 42.8 to $46 \%$ of cases $[9,10]$. However, in our series, these malformations are concerned only in $23.07 \%$ of patients, but this fact could reflect a deficiency in neuro-radiological exploration because of the high cost of neuroimaging examinations and their invasiveness.

\begin{tabular}{|l|l|l|}
\hline Evolutive aspects & Absolute values & Percentages (\%) \\
\hline Deceased & 4 & 30.76 \\
\hline $\begin{array}{l}\text { Number of people who } \\
\text { disappeared }\end{array}$ & 2 & 15.38 \\
\hline Ad integrum recovering & 3 & 23.07 \\
\hline $\begin{array}{l}\text { Neuropsychic } \\
\text { repercussions }\end{array}$ & 4 & 30.76 \\
\hline
\end{tabular}

Table 3: Apportionment according to the modalities of evolution.

Hematologic disorders including severe thrombocytopenia, homozygous sickle cell anemia and hemophilia are involved in 10-30\% of cases [1,12]. Among these hematological diseases, severe thrombocytopenia is the most frequently reported as a cause of HS, between $30 \%$ and $45 \%$ in the series $[9,11]$ while we had identified only one case of severe thrombocytopenia. These are idiopathic or usually secondary thrombocytopenia. [12] The search for a homozygous (SS) sickle cell disease was systematic in the context of a country where the disease is common. Strokes are common complications and hemorrhages account for $25 \%$ of strokes occurring in children with homozygous sickle cell disease (SS) [3].

Unlike adults, children are less likely to make cerebral hemorrhage of hypertensive origins unless values are important and hypertension is associated with other risk factors such as sickle cell disease and arteritis [7]. Cardiac causes are also reported in significant proportions [4], which is not the case in our series. If we can blame insufficient exploration to justify the fact that $61.53 \%$ of our patients have no identified cause, it is important to know that despite all the etiological explorations, no cause is found in 28.5 to $42.85 \%$ of child HS [4.10]. In a recent study Ciccone et al. found that low birth weight is associated to high risk of cardiovascular disease and kidney disease in adulthood [15].

Prognosis depends in part on the identification of the underlying etiology and sequelae; bleeding recurrence or death are common; full restitution ad integrum is rare [2,6,8,9]. $23.07 \%$ of the patients died in our series, which is in the range from $18 \%$ to $28.57 \%$ reported in the literature $[2,4,9,10]$. The same applies to neuropsychological sequelae 
Citation: Diop-Sène MS, Ousmane C, Ndiaye M, Diouf EM, Makhtar Ba MH, et al. (2016) Hemorrhagic Stroke: Clinical, Etiologic and Evolutive

estimated at 25 to $30 \%[2,4,11]$. The absence of recurrence in our series could be partly explained by the fact that patients were not followed for long periods.

The prognosis of children's HS is determined by the age of onset (the younger children are more likely to have a poor prognosis), the existence of an emboligenic cardiopathy behind the HS; the existence of seizures or persistent bleeding. These factors determine a large part of the care that will be definitely in accordance with the etiology found.

\section{Conclusion}

In Senegal many studies are devoted to HS in adults, while HS in children has never been a specific study in our country, this study is the very first. It will help to have a better diagnostic and etiological approach and thus to adapt the management and have a better monitoring to improve the prognosis.

\section{References}

1. Bejot Y, Osseby GV, Chantegret C, Gouyon JB, Huet F, et al. (2009) Les Accidents Vasculaires Cérébraux du nouveau-né et de l'enfant. Rev Neurol. 165: 899-900.

2. Broderick J, Talbot GT, Prenger E, Leach A, Brott T (1993) Stroke in children a major metropolitan area: the surprising importance of intracerebral hemorrhage. J Child Neurol 8: 250-255.

3. Chekoury A, Laporte M, Dupuy E (2008) The cerebro-vascular accidents and the sickle cell disease. STV. 20: 77-81

4. Chung B, Wong V (2004) Pediatric stroke among Hong Kong and Chinese subjects. Pediatrics 14: 206-212.

5. El-Hassani Y, De-Ribaupierre S, Sajadi A, Pereira VM, Rilliet B (2010) Spontaneous hemorrhagic cerebro-vascular accidents in children: etiologies and prise en charge. A Swiss medical review 6: 401-407.
6. Fullerton HJ, Wu YW, Sidney S, Johnston SC (2007) Recurrent hemorrhagic stroke in children: a population-based cohort study. Stroke 38: 2658-26562.

7. Humphreys RP (1992) Complications of hemorrhagic in children. Pediatric Neurosurg 17: 163-168.

8. Hladky JP, Lejeune JP, Blond S, Pruvo JP, Dhellemmes P (1994) Cerebral arteriovenous malformations in children: report on 62 cases. Childs Nerv Syst 10: 328-333.

9. Lori C, Jordan MD, Argye E, Hillis MD (2007) Hemorrhagic stroke in children. Neurol. Pediatr. 36: 73-80.

10. Merino Arribas JM, De-Pablo Chinchetru R, Grande-Grande T, Sanchez Martin J, et al. (1997) Non traumatic hemorrhagic stroke in children after the neonatal period. An Esp Pediatr 47: 392-396.

11. Psaila B, Petrovic A, Page LK, Menell J, Schonholz M (2009) Intracranial hemorrhage (ICH) in children with immune thrombocytopenia (ITP): study of 40 cases. Blood. 114: 4777-4783.

12. Roach ES (2000) Etiology of stroke in children. Semin Pediatr Neurol 7: 244-250

13. Roach ES, Colomb MR, Adams R, Biller J, Daniels S, et al. (2008) Management of stroke in infants and children: a scientific statement from a special writing group of the American Heart Association Stroke Council and the council on the Cardiovascular Disease in the Young. Stroke 39: 2644-2691.

14. Singhal A, Adirim T, Cochrane D, Steinbok P (2001) Pediatric patients with poor neurological status and arteriovenous malformation hemorrhage: An outcome analysis. Neurosurg Pediatr 7: 462-467.

15. Ciccone MM, Cortese F, Gesualdo M, Dl-Mauro A, Tafuri S, et al. (2016) The role of very low birth weight and prematurity on cardiovascular disease risk and on kidney development in children: A pilot study Minerva Pediatr 1: 29. 